\title{
Consideraciones en torno a la Ley de Privatización de ANTEL
}

La privatización de la Administración Nacional de Telecomunicaciones (ANTEL) ha sido uno de los principales bastiones del proceso general de privatización que se implementa desde 1990 , tanto por el carácter estratégico del sector telecomunicaciones en una economía global como por sus fuertes implicaciones polfticas. Desde el primer momento, la privatización de ANTEL fue presentada como una altemativa superior, tanto en términos económicos como sociales, para mantener esta empresa en manos del Estado. Algunos argumentos en favor de la privatización suponen que incrementaría el empleo en el sector telecomunicaciones, las remuneraciones anuales de los empleados, el número de líneas instaladas e, inclusive, provocaría reducciones en las tarifas del servicio. El reciente cambio en la correlación de fuerzas en el interior de la asamblea legislativa cuestionó el plan inicial de privatización delineado por el gobierno y obligó a nuevas discusiones y modificaciones.

El nuevo anteproyecto de ley para la privatización de ANTEL se discutió nuevamente por un período de 6 semanas, durante las cuales surgieron las más variadas posturas; desde la suspensión del proceso de privatización hasta la venta de la mayoría de acciones al sector privado; pero, al final, se conservó el espíritu original de la ley de otorgar la mayoría del capital accionario al sector privado, de esta manera, las modificaciones fueron únicamente en lo referente al porcentaje de acciones a la que debería acceder tanto el sector privado como los trabajadores, los usuarios y el Estado.

Así, a final de cuentas, las discusiones en tomo a la ley de privatización de ANTEL, motivadas en gran parte por la postura del partido FMLN de no venderla, no prosperaron porque no alteraron fundamentalmente el proyecto de privatización. En lo que sigue se trata de presentar una reseña del conflicto en torno a la revisión de este proceso de privatización, para luego presentar un breve análisis comparativo de los principales componentes de los dos anteproyectos de privatización que se han conocido durante el último año, tratando de colocar en perspectiva los principales cuestionamientos para la privatización de la Administración Nacional de Telecomunicaciones.

Originalmente, el anteproyecto, fechado el 28 de noviembre de 1996, contemplaba aspectos que se convirtieron luego en puntos de conflicto en la nueva asamblea legislativa que tomó posesión a partir del mes mayo. En gran parte, ello obedeció a que, después de las elecciones de marzo de 1997, la correlación de fuerzas se inclinó sensiblemente a favor de los detractores de la privatización, es decir, el FMLN. Algunos cuestionamientos mencionados por los diputados para aplazar la citada venta son: fijación de un precio por debajo del verdadero valor de mercado; utilización de los fondos obtenidos de la venta de ANTEL para cancelar la deuda pública interna de corto plazo y no para el gasto social, como originalmente se había ofrecido; y, finalmente, la forma en que el gobierno reemplazaría las utilidades aportadas por ANTEL al erario público.

Evidentemente esto gener 6 malestar, no sólo a nivel del gobiemo sino también a nivel del Banco Mundial, uno de los principales impulsores de la privatización alrededor del mundo, porque se abría 
la pósibilidad de retrasar, e incluso, suspender la venta de ANTEL. En este contexto se ubican las declaraciones del ahora ex Comisionado Presidencial para la Modernización del Estado, Alfredo Mena Lagos, del Presidente de la República, Armando Calderón Sol, y de funcionarios del Banco Mundial que visitaron el país con motivo del aplazamiento de la venta de ANTEL.

El citado ex Comisionado Presidencial habría expresado que, aunque considera sano el debate en la asamblea legislativa, la voluntad política del Gobiemo era no retrasar la venta de ANTEL. Al mismo tiempo, restó importancia al cuestionamiento sobre el precio de venta, al argumentar que éste fue realizado por empresas de prestigio y que estaría rondando los 500 millones de dólares. Por su parte, el Presidente Armando Calderón Sol habría expresado que pondría a disposición de la asamblea legislativa los argumentos en favor de la venta de ANTEL. Asimismo expresó que esperaría que esta situación fuera suficiente para evitar el verse en la necesidad de vetar iniciativas de ley que pretendan retrasar la venta de ANTEL.

En apoyo a las actitudes de los primeros, durante los primeros días del mes de julio pasado, el país y en especial la asamblea legislativa - fue visitado por una delegación del Banco Mundial, entre los que se encontraba el representante en el área de modemización y privatización del sector público. Este último centró sus argumentos en la importancia de utilizar nuevas opciones tecnológicas sin necesidad de que el Estado incurra en nuevos gastos que bien pueden invertirse en otros sectores, especialmente el soçial. Coincidió con planteamientos del gobiemo al sefialar que también se producirían importantes reducciones en las tarifas e indiscutibles mejoras en la prestación del servicio al facilitar el acceso a las comunicaciones a nivel mundial.

Pese a estas posturas y argumentos, a finales del mes de mayo la asamblea legislativa aprobó, incluso con el apoyo de los diputados del partido de gobierno, proceder a la revisión de la ley de privatización de ANTEL. A pesar de sus declaraciones iniciales, el Presidente no vetó esta iniciativa, con lo cual desencadenó reacciones encontradas en el entonces $\mathrm{Co}$ misionado Presidencial para la Modemización del Estado, quien incluso renunció poco después de que

el Presidente se negara a vetar.

Uno de los puntos más importantes discutidos fue la estructura de propiedad de la empresa de telecomunicaciones. El anteproyecto diseñado y aprobado durante la anterior legislatura contemplaba vender a socios estratégicos hasta un 51 por ciento de las acciones, a los trabajadores de ANTEL un 10 por ciento y al público en general el restante 39 por ciento. Es pertinente aclarar que los socios estratégi$\cos$ se consideran "aquellos inversionistas que tengan la capacidad para hacer una inversión tecnológica y financiera en las empresas por privatizarse y cuenten con la experiencia y tecnología necesarias para aumentar la cobertura y calidad de los servicios".

El nuevo anteproyecto de ley se diferencia de su precedente en que contempla que el Estado conserve parte de la propiedad de las compañías telefónicas. Así, se plantea la formación de dos diferentes compañías de telecomunicaciones: la compañía de la telefonía alámbrica y la compañía de la inalámbrica, cada una de las cuales se regirá por diferentes esquemas de propiedad. La compañía alámbrica pertenecería a cuatro diferentes tipos de propietarios: el socio estratégico (51 por ciento), el Estado y los consumidores (39 por ciento) y los trabajadores (10 por ciento). En cambio, el servicio inalámbrico quedaría en posesión de dos tipos de dueños: el Estado (49 por ciento) y el socio estratégico (51 por ciento).

Obviamente entre ambos tipos de privatización la diferencia fundamental es la permanencia del Estado en el negocio de las telecomunicaciones y la reducción de la participación del público en general. La propiedad privada de las nuevas empre- 
sas telefónicas que surgirían se limitaría fuertemente en relación con el proyecto original, pues el Estado conservaría un 49 por ciento de las acciones de la empresa de telefonía inalámbrica y parte del 39 por ciento del sistema alámbrico, con lo cual se eliminaría la participación del denominado "público en general", en especial, en la compañía inalámbrica.

Las implicaciones de estas modificaciones tienen relación con la restricción del acceso de inversionistas en general y, por supuesto, la reducción de los ingresos que percibirá el Estado por la suspensión de la venta de acciones en una proporción de $\mathbf{4 9}$ por ciento en la empresa inalámbrica y otra aún no definida en la empresa alámbrica.

La similitud de ambos anteproyectos es el porcentaje asignado a los socios estratégicos y a los trabajadores de las telecomunicaciones, en ambos casos el socio estratégico del Estado únicamente podrá acceder a un 51 por ciento del total de las acciones, lo cual, en cualquier sociedad mercantil, implica el control en la toma de decisiones. Asimismo se preservó el criterio de asignar a los trabajadores únicamente un 10 por ciento de las acciones.

Resulta claro que, en relación con el proyecto original, la Ley de Privatización de ANTEL permite al Estado acceso a los beneficios del negocio de las telecomunicaciones, sin afectar los intereses de posibles "socios estratégicos". Al mismo tiempo, mantiene el pequeño espacio creado para democratizar la propiedad de las empresas de telecomunicaciones. Las reformas al proyecto de privatización de ANTEL pues, no son substanciales, pues se mantiene el espíritu de vender su mayor parte a empresas transnacionales y ceder a éstas el manejo de las tarifas y las estrategias de la empresa.

Sin embargo, a pesar de la aprobación de la privatización de ANTEL, la verdad es que existen suficientes argumentos para sostener una postura escéptica ante este proceso de privatización por dos razones fundamentales: la inminente alza en las tarifas locales a consecuencia de la privatización; y segundo, el hecho irrefutable de que la operación de ANTEL genera fuertes ganancias contrariamente a lo que han venido afirmando los apologistas de la privatización.

El año pasado se conocieron las modificaciones que experimentarían las diferentes tarifas del servicio telefónico, que entraron en vigencia en agosto de 1996, las cuales contemplaron tres medidas: primero, un incremento de la cuota minima; segundo, una reducción de la duración del impulso telefónico a un tercio, lo cual supone de inmediato una triplicación de la facturación local; $y$, tercero, una reducción de las tarifas intemacionales que sólo afectó a aproximadamente un 45 por ciento del total de llamadas internacionales. Esta política se tomó con la clara intención de convertir a ANTEL en una empresa más rentable y, por tanto, más atractiva para posibles socios estratégicos interesados en su privatización.

Esta dinámica debería llamar a reflexionar sobre cuáles podrían ser los ajustes tarifarios que se operarian una vez privatizada ANTEL y eliminada la supervisión estatal de las tarifas telefónicas, tal como pretende la Ley de Telecomunicaciones. Es obvio que una vez en manos privadas, las tarifas telefónicas locales experimentarían nuevos incrementos y así lo reconocen, incluso, los consultores internacionales contratados para asesorar esta privatización. Cabe mencionar que para evitar los efectos negativos (eleccionarios y de imagen de la privatización) que se generarían con el incremento de las cuotas minimas ( $\sin$ contar el experimentado por las tarifas), los consultores proponían, maquiavélicamente, compensar a los 200,000 usuarios telefónicos con un monto de capital accionario de ANTEL equivalente a 1,000 colones.

Los incrementos de cuotas mínimas y de tarifas fueron ejecutados hace más de un año, sin embargo, aún se desconoce si se procederá a compensar a los usuarios por esta acción; aunque por las evidencias recientes más parece que las proyecciones son continuar con incrementos sustanciales de las tarifas. De acuerdo con los diputados del FMLN, dentro de la Ley de Telecomunicaciones, la cual regulará el funcionamiento de las nuevas empresas privadas de telecomunicaciones, se estaría contemplando proceder a un incremento tarifario que alcanzaría un total acumulado de más del 150 por ciento en relación con las tarifas vigentes.

Un segundo elemento que cuestiona la privatización de ANTEL es la inusitada publicación de sus estados financieros, un hecho nunca antes visto en la historia de esta institución aunque perfectamente explicable porque según un comunicado de ANTEL: "Esta auditoría independiente es una exigencia normal del sector financiero internacional para que empresas multinacionales 
contemplen la posibilidad de presentar ofertas de compra en una subasta pública de privatización".

Los estados financieros confirman las versiones de la Asociación de Trabajadores de las Telecomunicaciones en tomo a que las operaciones de ANTEL significan para el Estado una importante fuente de ingresos. Sólo para 1995, la firma encargada de la auditoría en mención, informó ganancias de 472 millones de colones, lo cual equivale a 85 por ciento del déficit fiscal para ese año. Con el ajuste tarifario registrado hace un año, sin duda que esta suma se habrá incrementado significativamente.

Un elemento adicional que se suma a los elementos en contra de la privatización de ANTEL, aunque con un efecto más limitado que el alza en las tarifas, es la reducción del empleo en el sector telecomunicaciones. De acuerdo con informes atribuidos a los mismos consultores de ANTEL, con la privatización de la misma podrían esperarse despidos que oscilarían entre los 500 y los 1,000 puestos de empleo que, al igual que las alzas tarifarias, tendrían elevados costos políticos que podrían reflejarse en las ya pasadas elecciones de marzo de 1997 y también podrian estigmatizar el proceso de modemización estatal al asociarlo con despidos masivos de empleados públicos. Aquí también se contaba con medidas cosméticas como, por ejemplo, garantizar a los trabajadores de ANTEL -cerca de 4,900- contratos de trabajo que vencieran después de las elecciones.

Los planteamientos del gobierno y de sus asesores sobre las bondades de la privatización de ANTEL (incremento del empleo en el sector telecomunicaciones, en las remuneraciones anuales de los empleados e, inclusive, reducciones en las tarifas del servicio), quedarían, pues, fuertemente cuestionados.

El panorama que configuran los datos anteriores muestra que, aunque podría darse por descontada la privatización de ANTEL, la verdad es que persisten cuestionamientos que no han sido resueltos aún con la discusión de este proceso de privatización. Por una parte, la política tarifaria que se insinúa mostrará una tendencia al alza, no solamente por el comportamiento del año pasado, sino también porque la Ley de Telecomunicaciones pretende dejar el campo libre para que las compañías que adquieran ANTEL, o socios estratégicos, fijen a su antojo las tarifas telefónicas. Por otra parte, los estados financieros de ANTEL muestran que, en este caso, el argumento de que la privatización liberará al Estado de gastos para mantener operando a las empresas públicas es falso. Muy por el contrario, al proceder a privatizar se estaría renunciando a un apreciable monto de ganancias provenientes de la operación de la empresa telefónica. Cabe señalar que esto se aplica no sólo a ANTEL, pues de acuerdo con los datos del Banco Central de Reserva, por lo general, el conjunto de empresas públicas no financieras arrojan a final del año un considerable superávit de operación.

La privatización de ANTEL, pues, implicaria incremento de las tarifas locales, pérdida de inguesos públicos potenciales y, muy posiblemente, despidos masivos en el sector de telecomunicaciones. A cambio, el país recibiría todo el conocimiento y la tecnología que los "socios estratégicos", bondadosamente, están dispuestos a compartir. Es obvio que el trasfondo de la privatización de las telecomunicaciones es una ampliación de los campos de acumulación del sector privado y, muy especialmente, del capital transnacional, históricamente ligado a la extracción de riquezas desde los países del sur en beneficio de los países del norte.

En el plano político, las dinámicas alrededor de la privatización de ANTEL dejan la impresión que la iniciativa inicial del FMLN de revisar el proceso no habría tenido mayor éxito; en especial al considerar que se pronunció por no vender ANTEL sin lograr el apoyo necesario para impulsar esta iniciativa. La postura del FMLN en el proceso de discusión de la ley de privatización lo llevó a retirarse en el momento que se reunieron los votos necesarios para llevar al pleno el nuevo proyecto de privatización. A final de cuentas, el partido oficial, acompañado de varios partidos minoritarios, consensaron la venta mayoritaria de ANTEL al socio estratégico, tal y como se planté desde el inicio.

No puede negarse que esto fue un importante espaldarazo para el partido de gobiemo, porque logró sacar adelante la privatización de las telecomunicaciones sin necesidad de recurrir al veto presidencial. En cambio, los detractores del proceso de privatización aparecen ahora con menos argumentos, y menos capacidad política, para oponerse al proceso. Paradojicamente, es en este momento que el gobierno aparenta baber retrocedido en su plan de privatización, a juzgar por las declaracio- 
nes de la nueva Comisionada Presidencial para la Modernización del Sector Público que sugieren que no se proyectan nuevas privatizaciones.

El único punto a favor de la discusión en tomo a la privatización de ANTEL es que el Estado logró conservar su participación en las utilidades de las empresas de telecomunicaciones, pues el pro- yecto original la había eliminado totalmente. Por lo demás, no es posible notar cómo la privatización puede contribuir al desarrollo, si ni siquiera garantiza mayor generación de empleo y estabilidad en los precios de los servicios.

Luis Ernesto Romano 